WellBeing International

WBI Studies Repository

9-1993

\title{
Vocal Perception: Brain Event-Related Potentials in a Chimpanzee
}

\author{
Gary G. Berntson \\ Ohio State University \\ Sarah T. Boysen \\ Ohio State University \\ Michael W. Torello \\ Ohio State University
}

Follow this and additional works at: https://www.wellbeingintlstudiesrepository.org/acwp_asie

Part of the Animal Studies Commons, Comparative Psychology Commons, and the Other Animal Sciences Commons

\section{Recommended Citation}

Berntson, G. G., Boysen, S. T., \& Torello, M. W. (1993). Vocal perception: Brain event-related potentials in a chimpanzee. Developmental psychobiology, 26(6), 305-319.

This material is brought to you for free and open access by WellBeing International. It has been accepted for inclusion by an authorized administrator of the WBI Studies Repository. For more information, please contact wbisr-info@wellbeingintl.org.

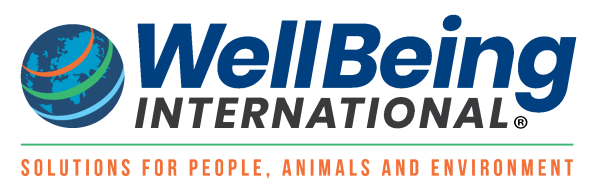




\title{
Vocal Perception: Brain Event-Related Potentials in a Chimpanzee
}

\author{
Gary G. Berntson $^{1,2}$, Sarah T. Boysen ${ }^{1,2}$, and Michael W. Torello ${ }^{1}$ \\ ${ }^{1}$ Ohio State University \\ ${ }^{2}$ Emory University
}

\begin{abstract}
$\underline{\text { ABSTRACT }}$
We describe the first brain event-related potential (ERP) study of cognitive processes in the chimpanzee. In an extension of our studies on the ontogeny of vocal perception, ERP measures were obtained during the presentation of simple nonsignal stimuli as well as conspecific and human vocalizations. We initially confirmed findings from humans and monkeys of the appearance of a long-latency positivity in the ERP waveform to a rare stimulus in an oddball paradigm. This ERP component is reminiscent of the P3a reported in humans under similar (passive) experimental conditions. We further demonstrated that both conspecific and human vocal stimuli having affective significance also enhanced late positive components of the ERP. These late positive components displayed a predominant fronto-central distribution, with a maxima at Cz. Additionally, responses to adaptively significant vocal stimuli showed a right hemisphere laterality, whereas no significant laterality was observed with the rare stimulus in the oddball paradigm. Results document the feasibility of ERP measures in chimpanzees and their potential utility in the study of the ontogeny and phylogeny of vocal perception.
\end{abstract}

\section{Introduction}

Perception of vocal signals is essential for social interaction and communication in a wide range of species. In some cases, specialized perceptual mechanisms may contribute to inherent reactions to species-specific vocalizations, although perceptual learning also appears to play a prominent role, especially in primates. Indeed, vocal-perceptual learning has been documented in utero in human infants (DeCasper \& Prescott, 1984; DeCasper \& Spence, 1986). Even for humans and other primates, however, aspects of the perceptual response to vocal signals may be constitutionally disposed (Newman, 1985; Seyfarth, 1987; Snowdon, 1982). A considerable literature on the ontogeny of acoustic perception in primates documents an early appearance of selective processing mechanisms for vocal stimuli in infants (Ash, Pisoni, \& Jusczyk, 1983; Kuhl, 1987b; Molfese \& Beltz, 1987; Morse, Molfese, Laughlin, Linnville, \& Wetzel, 1987; Trehub, 1987). Considerable phylogenetic continuity exists in the acoustic features of human and nonhuman infant cries (Lieberman, Harris, Wolff, \& Russel, 1971; Newman, 1985), and cries may evoke similar perceptual reactions in human and nonhuman primates (Bryan \& Newman, 1988). More general features of acoustic perception also appear similar across primate species (Liberman, Cooper, Shankweiler, \& Studdert-Kennedy, 1967). These include the categorical perception of continuously graded phonemes, where nonhuman primates demonstrate perceptual boundaries comparable to those of humans (Kuhl, 1987a; Petersen, 1982; Snowdon, 1982). Moreover, both human and nonhuman primates evidence lateralized hemispheric processing of specific vocal signals (Kuhl, 1987a; Morse et al., 1987; Petersen, 1982; Peterson et al., 1984; Pohl, 1983; Snowdon, 1982). These 
features suggest at least partially overlapping modes of processing for vocal signals in human and nonhuman primates, and raise important questions over the contributions of learning and constitution to vocal perception.

In view of these considerations, a further understanding of vocal processing in nonhuman primates may not only enhance our appreciation of vocal communication in these species, but may offer insights into the evolution of language processes. From a phylogenetic perspective, the chimpanzee represents an ideal model for such an inquiry. Chimpanzees appear to be our closest extant relatives, and the vast preponderance of our genetic material is shared in common with this species (Goldman, Giri, \& O'Brien, 1987; Goodman, Braunitzer, Stangl, \& Shrank, 1983). Like humans, chimpanzees are a highly social and highly vocal species. They demonstrate among the highest cognitive capacities of nonhuman animals, and evidence lateralized enlargement of cortical areas corresponding to those which have been implicated in vocal processing in humans (Boysen \& Berntson, 1989b; Essock-Vitale \& Seyfarth, 1987; LeMay \& Geschwind, 1975; Premack, 1986; Yeni-Komshian \& Benson, 1976).

In previous studies of the ontogeny of vocal perception in apes, we found that infant chimpanzees showed a distinct and species-specific psychophysiological response to conspecific threat barks (Berntson \& Boysen, 1989). Within hours of birth, and without prior exposure to the stimuli, infant chimpanzees uniformly displayed a notable cardiac acceleration to threat barks. This response differed from the predominant cardiac deceleration of infant orangutans to this same vocal stimulus, and from the responses of the same chimpanzees to other conspecific vocalizations. The species-specific cardioacceleratory response to threat was highly reminiscent of the defensive reaction evoked by pain or fear-arousing stimuli (Berntson \& Boysen, 1990). The uniform appearance and early emergence of this response to threat are consistent with the view that chimpanzees may be endowed with perceptual mechanisms that are tuned to specific features of conspecific vocalizations and inherently linked to patterns of affective response. We extend these psychophysiological studies of vocal perception in apes through an examination of the brain event-related potentials of a young chimpanzee to vocal stimuli.

Event-related potentials (ERPs) represent time-locked electroencephalographic responses to a specific stimulus or event, and have been shown to covary with cognitive and/or attentional processes. In particular, long latency components of the ERP waveform have been considered endogenous or processing-contingent potentials because of their sensitivity to the cognitive processing of the stimuli (Picton \& Hillyard, 1988; Steinschneider, Kurtzberg, \& Vaughan, 1992). An example of the latter is the P300, a positive-going potential with a typical latency between 300 and $500 \mathrm{msec}$. The P300 is distributed primarily over central scalp regions, and its amplitude has been shown to be closely related to the subjective probability and meaningfulness of the stimulus (Donchin, Karis, Bashore, Coles, \& Gratton, 1986; Johnson, 1988, 1993; Johnston, Miller, \& Burleson, 1986). In addition to the classical P300, there appears to be a family of late positive components (Late Positive Complex), with differing latencies, waveforms, scalp distributions, and cognitive correlates (Courchesne, Hillyard, \& Galambos, 1975; Ruchkin, Sutton, \& Mahaffey, 1987; Sutton \& Ruchkin, 1984).

ERPs are especially useful because they do not depend upon the behavioral repertoire of the subject, and hence are broadly applicable across ontogeny and phylogeny. They offer important measures that may tap intermediate stages between sensory processing and response generation. We previously demonstrated that brain ERPs recorded from chimpanzees are highly similar to those of humans (Boysen \& Berntson, 1985). For the current experiments, we apply ERP measures to explore the perceptual processing of vocal signals in a chimpanzee. We further employ a full complement of 28 EEG electrodes to permit a topographic mapping of the scalp topography of the ERPs. 


\section{Method}

Subject

The subject was a 6.5-year-old juvenile female chimpanzee (Sheba), who had been a previous participant in our developmental studies of cardiac reactivity to conspecific vocalizations (Berntson \& Boysen, 1989; Berntson, Boysen, Bauer, \& Torello, 1990). Sheba had been involved extensively in social and behavioral training programs in the Ohio State University Primate Cognition Project (e.g., Boysen \& Berntson, 1989a, 1989b).

\section{Stimuli}

Stimuli consisted of simple tones, conspecific vocalizations, and human speech. For the oddball paradigm of Experiment 1, 40-msec epochs of pure tones ( 500 and $1500 \mathrm{~Hz}, 80 \mathrm{db}, 10 \mathrm{msec}$ rise time) were generated by the ERP system and presented by TDH 75 headphones. The remaining stimuli were recorded on high fidelity tape, filtered at $4 \mathrm{kHz}$, and computer digitized at $8 \mathrm{kHz}$. In all cases, stimuli were equated to $76 \mathrm{db}$ (SPL), and presented under computer control via TDH 75 headphones. For Experiment 2 , the speech stimulus was a $350-\mathrm{msec}$ verbalization of the subject's name (Sheba) by the primary human caregiver. The control stimulus was a $500-\mathrm{Hz}$ square wave tone of the same duration. The conspecific vocalizations of Experiment 3 were recorded from other animals of the OSU Primate Cognition Project during actual social encounters. Vocalization stimuli included $300-\mathrm{msec}$ epochs of threat barks, stress screams, and alarm calls. A broadband white noise stimulus of the same duration served as a control. The threat vocalization consisted of a guttural coughlike utterance, alarm entailed a higher pitched "hoo"like call, and stress vocalization consisted of a continuous scream. These vocalizations corresponded in context and character to the bark (Marler \& Tenaza, 1977), hoo (van Lawick-Goodall, 1968), and scream (Marler \& Tenaza, 1977; van Lawick-Goodall, 1968) vocalizations as previously described for the common chimpanzee. The spectral composition of these stimuli was reported in a previous heart rate study which employed these vocal tokens (Berntson \& Boysen, 1989). Because the acoustic envelope can be a critical feature of vocal signals, we did not taper or control the rise times of the vocal stimuli.

\section{ERP Measures}

EEG signals were recorded by an array of 28 scalp electrodes, including the 20 sites of the international 10-20 system, together with $\mathrm{CP}_{1} / \mathrm{CP}_{2}, \mathrm{TOP}_{1} / \mathrm{TOP}_{2}, \mathrm{FTC}_{1} / \mathrm{FTC}_{2}$, and $\mathrm{PO}_{1} / \mathrm{PO}_{2}$. In addition, six artifact electrodes were employed (suprainfraorbital, right-left canthi, and right-left masseters). All electrodes were referenced to linked ears, with FP, serving as ground. Signals were processed by a Neuroscience Series II ERP acquisition system (12-bit digitization, 2-msec sample time, 16-msec prestimulus, and 600msec poststimulus epochs). EEG filters were set at $.1 \mathrm{~Hz}$ and $30 \mathrm{~Hz}$. Artifacts were automatically rejected (any channel exceeding $64 \mu \mathrm{V}$ ), and the remaining traces were averaged separately for each electrode site. For all conditions, 20 artifact-free traces were obtained in each acquisition block, and results were replicated in two or more blocks to insure reliability. Artifacts generally occurred on less than $25 \%$ of the trials, and no notable differences were apparent in the number of EEG artifacts across the experimental stimuli. Artifacts generally reflected declining sedation, and testing was suspended if artifacts exceeded $50 \%$.

\section{General Procedure}

All testing was accomplished in a quiet, darkened room. Stimuli were controlled by the Neuroscience acquisition system or in the case of digitized stimuli, by a stand-alone microprocessor based system. Interstimulus intervals were $2 \mathrm{~s}$. No explicit training was given, and no task demands were imposed. The 
animal was lightly sedated with droperidol $(1 \mathrm{mg})$ and ketamine (as necessary) for electrode attachment and testing. ${ }^{1}$ In view of the necessity for sedation, an important behavioral criterion for testing was that the animal remain behaviorally attentive and responsive to environmental events and the verbal commands of the experimenters. A criterion for testing was that the animal physically orient to the experimenter when the subject's name was called. To further evaluate the attentional state of the subject, the first experiment entailed a standard P300 oddball paradigm.

The oddball paradigm was employed to extend the P300 results from humans, and to insure the sensitivity of the subject to the probability of environmental stimuli. In human subjects, a late positive (P300) component emerges in the ERP response to an infrequent stimulus embedded in a stream of frequent stimuli. The P300 has been shown to be related to both the subjective probability and informational significance of the rare tone (Johnson, 1988, 1993). Although the P300 is substantially enhanced by imposing a response demand on the occurrence of the rare stimulus (e.g., counting, pressing a button, etc.), typical P300 responses can be seen even in the absence of an explicit response (Neville \& Foote, 1984; Pineda, Foote, \& Neville, 1987; Polich, 1987). In the present study, no training or task demands were imposed. Stimuli consisted of pure tones of two frequencies (500 and $1500 \mathrm{~Hz}$ ), with the probability of one stimulus being $85 \%$ and the other $15 \%$. A total of six blocks were acquired over two sessions, with both the $500 \mathrm{~Hz}$ and $1500 \mathrm{~Hz}$ tones serving as the rare stimulus in separate blocks. In each block, the first 20 artifact-free traces were acquired for both the rare and the frequent stimulus.

Stimulus meaning or significance can enhance long latency potentials, like the P300 in humans (Johnson, 1988, 1993), and this issue is of particular interest for studies of vocal perception in chimpanzees. In a third session, we examined the sensitivity of the late ERP components to the information or adaptive significance of the stimuli. To evaluate the sensitivity of the ERP to stimulus significance in the chimpanzee, we recorded brain ERPs to two stimuli differing in adaptive meaning to the animal. The stimuli consisted of a 350-msec (500 hz) tone and a 350-msec epoch of human speech (the animal's name, Sheba). Four blocks of 20 artifact-free traces were obtained for each stimulus. To avoid confound from potential local variations in stimulus probability, only a single stimulus type was presented within a given block so that the probability of a given stimulus was either 1 or 0 . The order of stimulus administration was counterbalanced across blocks. Other procedural details were as outlined earlier.

In a final session, we examined the ERP responses to brief epochs of the conspecific vocal stimuli we previously tested with heart rate measures. General procedures followed those described earlier. Briefly, 300-msec epochs of white noise as well as conspecific threat, alarm, and scream vocalizations were presented in separate blocks. A single stimulus was presented during a given block, with at least 20 artifact-free traces acquired. Each stimulus was presented in two separate blocks, with the order of stimuli counterbalanced across blocks.

\section{Data Analysis}

Averaged waveforms were derived separately for the individual ERP acquisition blocks (minimum 20 traces), as outlined earlier. Graphic illustrations depict the overall means and standard errors (across replicate blocks) of the obtained waveforms for a given stimulus. Our primary interest was in the late positive components of the ERPs, which are generally focused around the central scalp. Consequently, statistical analyses were generally based on peak and mean waveform voltages at the central electrode $(\mathrm{Cz})$ over the latter half of the epoch. The late positive component was maximal between $350-550 \mathrm{msec}$, and peak values were derived from this epoch. To more appropriately capture the full waveform components, averages were taken over a broader 300-600 msec period (i.e., the last half of the acquisition epoch). The primary analyses were by dependent $t$ tests on relevant experimental contrasts. All statistical tests were two-tailed. 
The scalp distributions of waveform components are illustrated by topographic difference maps that depict the differences in waveform amplitudes, across all 28 EEG electrodes, for the test and comparison waveform (e.g., rare vs. frequent stimulus), In all cases, maximal ERP responses were focalized in the central scalp area. Consequently, measures of laterality were based on the immediate parasagittal electrodes over the central scalp area. Laterality of waveform components was evaluated by a 2 (stimulus type) $\times 2$ (laterality) repeated measures ANOVA on the mean amplitudes for right and left electrodes in the central scalp regions (F3/F4, C3/C4, and CP1/CP2).

\section{Results}

\section{Oddball Paradigm}

Consistent with results from humans, a late positivity to a rare stimulus was apparent in ERPs of the chimpanzee subject. Results are illustrated in Figure 1a, which depicts the overall ERP waveforms to the frequent and infrequent stimuli (120 traces over six acquisition blocks), as well as the standard errors of these waveforms. The rare stimulus was associated with a long-latency positivity, which peaked between $350-550 \mathrm{msec}$. Although the positive peaks were distinct on a given run, considerable latency variation was apparent between runs, $440 \mathrm{msec} \pm 57.9 \mathrm{SD}$. This gives the spurious appearance of a low frequency positivity in the overall waveforms of Figure 1a. No differences were apparent between the rare and frequent stimuli in the latency of the late positive peak (440 vs. $441 \mathrm{msec}$ at Cz, respectively). The amplitudes of the peaks, however, were significantly larger for the rare stimulus. The mean peak amplitude for the six runs with the rare stimulus was $12.2 \mu \mathrm{V}( \pm 2.0 \mathrm{SEM})$ compared to $3.1 \mu \mathrm{V}( \pm 1.4$ SEM) for the frequent stimulus, $t(5)=5.88, p=.002$. Similarly, the average voltage of the ERPs over the 300- to 600-msec interval were significantly different for the rare and frequent stimuli, mean for the rare stimulus $=6.8 \mu \mathrm{V} \pm 2.6 \mathrm{SEM}$; for the frequent stimulus $=-1.3 \mu \mathrm{V} \pm 1.6 \mathrm{SEM} ; t(5)=3.46, p=.02$.

The scalp distribution of the late positive component of the ERP to the rare stimulus was predominantly fronto-central. This is illustrated in Figure $2 \mathrm{a}$, which shows the distribution of the difference waveform (ERP to the rare stimulus minus the ERP to the frequent stimulus) averaged over the 300- to 600-msec epoch. Comparison of the amplitudes of the late positivity for right and left pericentral electrodes (F3/F4, $\mathrm{C} 3 / \mathrm{C} 4, \&$ CP1/CP2) revealed no significant laterality. The difference waveforms between the rare and frequent stimuli, for example, averaged $9.2 \mu \mathrm{V}( \pm .7 \mathrm{SEM})$ on the right (F4, C4, \& CP2) and $8.4 \mu \mathrm{V}( \pm 1.0$ SEM) on the left (F3, C3, \& CP1).

\section{Stimulus Meaning}

Components of the late positive complex in humans are known to be enhanced by stimulus meaning (Johnson, 1988, 1993) or affective significance (Johnston et al., 1986). To examine the impact of significance of the acoustic stimulus, we measured ERPs to a human vocalization of the subject's name (Sheba), compared to a simple tone stimulus. Each stimulus was tested in four separate counterbalanced runs of 20 trials. For any given run, therefore, stimulus probability was either 1 or 0 . Results are illustrated in Figure 1b, which depicts the overall ERP waveforms to the vocal and control stimuli (80 traces over four acquisition blocks), and the standard errors of these waveforms. As expected, the vocal stimulus was associated with a long-latency positivity. As was the case for the ERP to the rare stimulus, this late positivity peaked between 350-550 msec. Again, the positive peaks were distinct on a given run, although considerable latency variation was apparent, $446 \mathrm{msec} \pm 57.7 \mathrm{SD}$. No significant differences were seen between the vocal and control stimuli in the latency of the late positive peak (446 vs. $41.5 \mathrm{msec}$ at Cz, respectively). The amplitudes of the late positive peaks, however, were significantly larger for the vocal stimulus. The peak amplitude at central scalp for the four runs with the vocal stimulus was $12.9 \mu \mathrm{V}(\mathrm{r} 2.8$ SEM) compared to $2.7 \mu \mathrm{V}( \pm 1.6 \mathrm{SEM})$ for the control stimulus, $t(3)=3.7, p=.02$. The overall average 
voltages of the ERPs over the 300- to $600-\mathrm{msec}$ interval were also more positive for the vocal and control stimuli, mean for the vocal stimulus $=6.9 \mu \mathrm{V}( \pm 2.7$ SEW; mean for the control stimulus $=-1.7 \mu \mathrm{V}( \pm 2.8$ $S E W$, although this difference failed to achieve significance, $t(3)=2.25, p=n s$.

Fig. 1. Event-related brain potentials of a juvenile chimpanzee. (A) Averages (thick lines) and standard errors (thin lines) of ERP waveforms to rare and frequent stimuli in an oddball paradigm. (B) Averages (thick lines) and standard errors (thin lines) of ERP waveforms to a human speech stimulus and a tone control stimulus. (C) Average ERP waveforms to three conspecific vocalizations and a white noise stimulus. (Figure inserts depict representative results from single acquisition runs of 20 trials.)
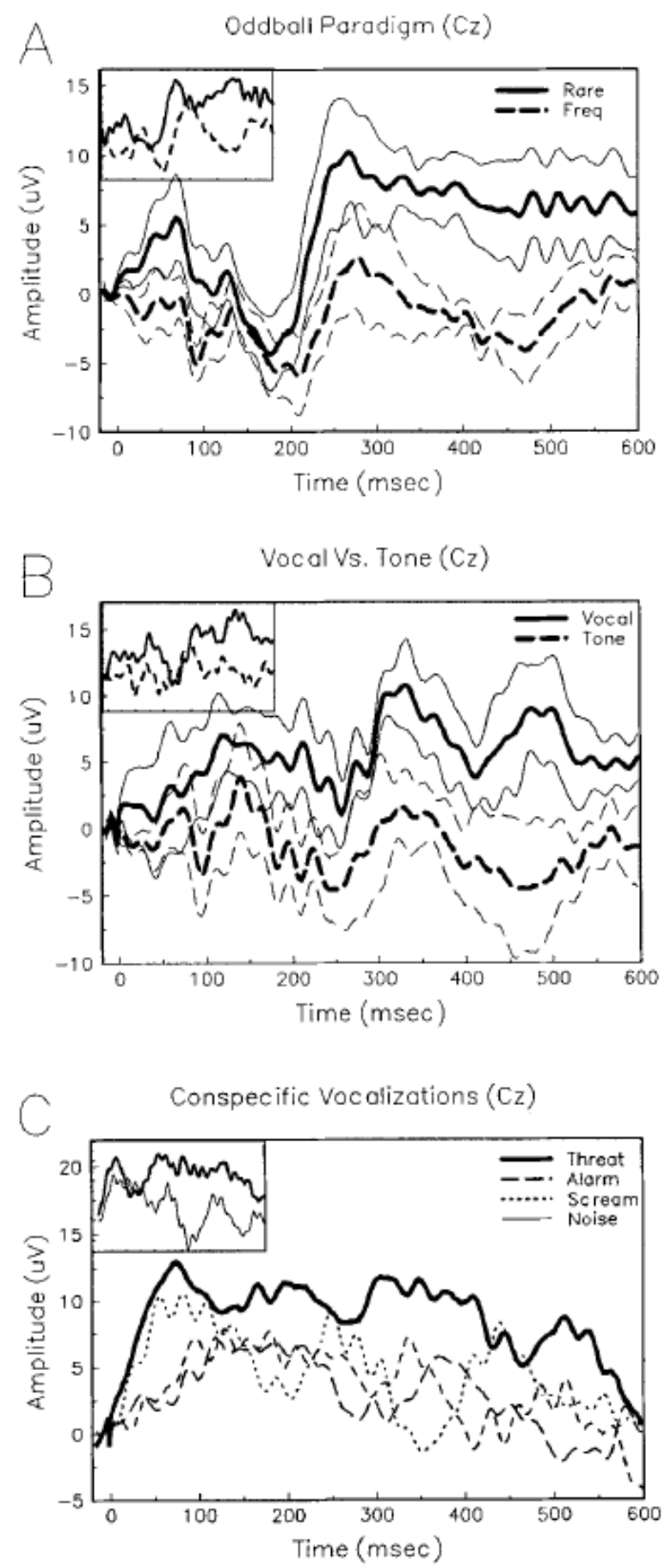
Fig. 2. Scalp distribution of late positive components of the ERPs. Topographic maps illustrate the topographic distribution of the difference waveforms between the ERP to the target stimulus minus the ERP to the control stimulus. Up is anterior and down is posterior.
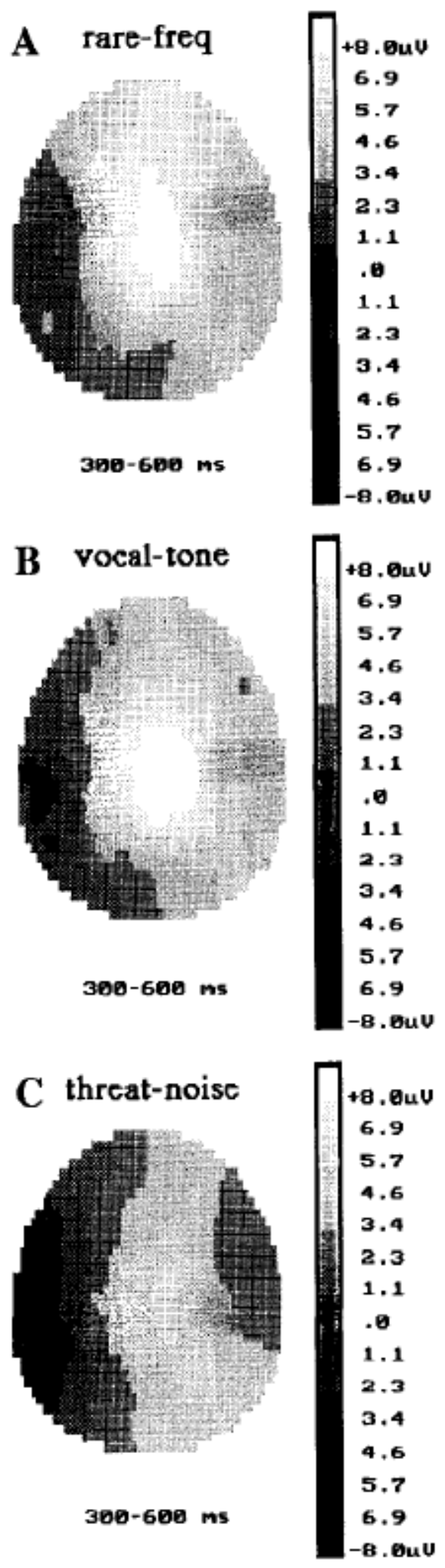
The scalp distribution of the late positive component of the ERP to the vocal stimulus was again predominantly fronto-central. This is illustrated in Figure $2 \mathrm{~b}$, which shows the distribution of the difference waveform (ERP to the vocal stimulus minus the ERP to the control stimulus) averaged over the 300- to $600-m s e c$ epoch. To evaluate the lateral symmetry of the late positive component, we compared the relative amplitudes at pericentral electrodes on the left and right sides. For each acquisition block (4 tone and 4 vocal), the average peak amplitude of the late positive component was determined for the three pericentral electrodes on the right ( $\mathrm{F} 4, \mathrm{C} 4$, and CP2) and the corresponding electrodes on the left (F3, $\mathrm{C} 3$, and CP1). These data were analyzed by a repeated measures ANOVA according to a 2 Stimulus Type (tone vs. vocalization) $\times 2$ Laterality (right vs. left) design. A significant Stimulus Type $\times$ Laterality interaction, $F(1,3)=16.84, p=.02$, reflected the right lateral dominance of the late positive component of the ERP to the vocal stimulus, mean amplitude on right $=10.9 \mu \mathrm{V}( \pm 2.4$ SEM $)$, left $=7.2 \mu \mathrm{V}( \pm 2.5$ SEM). No lateral differences were apparent in the late component of the ERP to the tone control stimulus, mean amplitude on right $=2.2 \mu V( \pm 2.3 \mathrm{SEW}$, left $=1.9 \mu \mathrm{V}( \pm 3.5 \mathrm{SEM})$. The lateral differences between the vocal stimulus and the tone were apparent in the difference waveform (vocal stimulus minus the control stimulus), which evidenced a peak of $11.7 \mu \mathrm{V}( \pm 1.4)$ on the right, and $8.6 \mu \mathrm{V}( \pm 1.7)$ on the left.

\section{Conspecific Vocalizations}

In view of the previous findings, we pursued additional exploratory studies on ERP responses to conspecific vocalizations. While the human vocalization tested above yielded an enhanced late positive component in the ERP, it is not entirely clear whether this positivity arose from the meaningfulness of the stimulus, per se, or from some other feature such as acoustic complexity. To examine this issue further and to explore responses to conspecific vocalizations, we acquired ERP responses to presentations of digitized epochs of chimpanzee threat, scream, and alarm vocalizations, and to a white noise control stimulus. We previously demonstrated that threat barks evoke a distinct pattern of autonomic and attentional response, reminiscent of a defensive reaction, while the other conspecific vocalizations yielded responses comparable to those to white noise (Berntson \& Boysen, 1990). Based on the apparent adaptive significance of threat, we expected this vocalization to yield an enhanced late positive component of the ERP. Moreover, we expected this-component to be larger over the right hemisphere.

Results confirmed both hypotheses. The overall ERP waveforms to the experimental stimuli are illustrated in Figure 1c. Each waveform represents a total of 40 trials for each stimulus, acquired in separate runs (20 trials each) administered in counterbalanced order. As is apparent, the threat bark evoked a considerably larger late positive deflection than any of the other stimuli, which did not appreciably differ from each other. As illustrated in Figure 2c, this late positivity was distributed centrally and was larger over the right hemisphere. Although the limited number of replications precluded parametric comparisons, a confirmatory analysis of the two hypotheses was significant even by nonparametric methods. For both replicate runs, the amplitude of the late positive peak to the threat stimulus was larger than for any other stimulus, which did not differ among themselves, mean for threat $=13.3 \mu \mathrm{V} \pm 1.0$, noise $=8.4 \mu \mathrm{V} \pm 2.24$, scream $=7.5 \mu \mathrm{V} \pm 1$, alarm $=7.3 \mu \mathrm{V} \pm 6.8$. Moreover, the late positive potential to threat was larger over the right hemisphere, peak: right $=10.9 \mu \mathrm{V} \pm 1.4$, left $=7.3 \mu \mathrm{V} \pm .3$; average: right $=4.9 \mu \mathrm{V} \pm .6$, left $=2.9$ $\mu \mathrm{V} \pm .5$. A simple binomial test of the probability of these outcomes (i.e., that the threat response was larger than all others, and larger on the right) yielded a $p=.03$. The larger late positivity associated with the threat vocalization did not appear to be attributable to simple acoustic features of the stimulus because amplitudes were matched among the stimuli, and the white noise stimulus included all acoustic frequencies in the threat signal (see Berntson \& Boysen, 1989a). Moreover, the rise time characteristics of the threat stimulus were similar to those of the alarm call, which did not yield an enhanced positivity relative to the noise stimulus. 
The threat vocalization also evoked an early positivity that exceeded that for other vocal stimuli. The origin of this early positive response is not clear, although it did not appear to be related to the adaptive significance of the threat vocalization. A similar early positivity was apparent to the white noise stimulus. We did not control the rise times of these vocalizations because the acoustic envelope can be an important feature of the vocal signal. The threat bark and noise stimuli both had somewhat faster rise times than did other vocal stimuli, and this may have contributed to the enhanced early positivity observed with these stimuli.

\section{Discussion}

We previously reported that visual evoked potentials in infant chimpanzees are highly similar to those of humans, and evidence comparable developmental trends in peak latencies and amplitudes (Boysen \& Berntson, 1985). Additional work in monkeys has documented characteristic long-latency potentials (such as the P300) in nonhuman primates that are sensitive to cognitive variables (Arthur \& Starr, 1984; Neville \& Foote, 1984; Paller, Zola-Morgan, Squire, \& Hillyard, 1982; Pineda et al., 1987). The present results provide the first documentation of the cognitive sensitivity of long-latency ERP components of a chimpanzee. In a passive oddball paradigm, the infrequent stimulus yielded an enhanced late positive potential, reminiscent of the P300 reported for humans under comparable conditions.

A number of late positive components, including a positive slow wave and several P300 variants (e.g., P3a, P3b, P3e), have been identified in humans (Courchesne et al., 1975; Ruchkin et al., 1987; Sutton \& Ruchkin, 1984). The P3b is sensitive to subjective probability and stimulus meaning in oddball paradigms, and is significantly enhanced by the task relevance of the stimulus (Johnson, 1988, 1993). This component generally shows a predominant centro-parietal distribution, with a maximum at $\mathrm{Cz}$ or $\mathrm{Pz}$. An essentially similar component has been observed in monkeys in a task performance context (Arthur \& Starr, 1984). While the late positive potential to the rare stimulus in the chimpanzee was generally similar to the P3b in latency and amplitude, the late positivity in the chimpanzee was somewhat more frontally distributed than would be expected of the P3b. In this respect, the late positive component of the chimpanzee was more similar to the fronto-central P3a, as observed in both humans (Courchesne et al., 1975; Squires, Squires, \& Hillyard, 1975) and monkeys (Paller et al., 1982; Pineda et al., 1987). Consistent with the procedures of the present study, the P3a is more frequently observed in passive oddball paradigms that lack explicit task demands, although a more frontal distribution is not invariably observed in passive P3 paradigms (Polich, 1987). Pineda and colleagues (1987) have reported in squirrel monkeys what they term a "monkey" late positive component, which is characterized by two positive peaks and is sensitive to infrequent and unpredictable shifts in pitch (Pineda et al., 1987). The precise relationships among these components of the late positive complex are not entirely clear, and the late positivity observed in the chimpanzee cannot at the present time be definitively identified with a specific human or monkey homologue. Nevertheless, the late ERP positivity to the rare tone in the chimpanzee shares a common feature with components of the late positive complex-a sensitivity to stimulus probability.

Affective significance of a stimulus is known to increase late positive potentials in humans (Johnston et al., 1986). In the present study, a late positivity was apparent in the ERP waveforms of the chimpanzee to the vocalization of the subject's name, relative to a control tone. This late positivity was generally similar in latency and amplitude to that observed to the rare tone in the oddball paradigm, but in the present case could not be attributed to differences in stimulus probability. Rather, the results are in general accord with the findings that late positive components of the ERP may be enhanced by the affective or attentional significance of a stimulus. In the present case, the vocal stimulus was spoken by the primary caregiver, with whom the subject had established a strong social bond. This likely contributed to the significance of the vocal stimulus. 
Based on our previous finding of a selective and striking cardioacceleratory response of infant chimpanzees to conspecific threat barks (Berntson \& Boysen, 1989), we speculated that the affective and attentional properties of the threat vocalization would be associated with an enhanced late ERP positivity. Results were in accord with this expectation. The threat vocalization yielded a greater late positivity than either white noise or other conspecific vocal stimuli (screams and alarm calls). Although these findings require confirmation, they illuminate several issues. First, the enhanced late positivity does not appear to be specific to human or chimpanzee vocalizations, but may be seen with either. Second, because late ERP components to screams and alarm calls were not different from those to white noise, it does not appear that all vocalizations invariably enhance late positive potentials. Rather, the communicative or affective significance of the vocalization may be the more important determinant. Finally, the direction of heart rate response can distinguish between orienting and defensive responses. We have found that chimpanzees respond with cardiac acceleration to threat barks, and with deceleration to a caregiver (Berntson \& Boysen, 1990; Boysen \& Berntson, 1986). Both the caregiver vocalization and threat barks, however, resulted in an enhancement of late positivity in the ERP. Consistent with findings in humans, the enhanced late positivity observed in chimpanzees appears to be more reflective of the intensity rather than the direction of affective response.

An additional feature of the present results that warrants comment is the laterality of the obtained ERPs to specific vocal stimuli. The late positivity to the rare stimulus in the oddball paradigm was essentially symmetrical over the two hemispheres. In contrast, the late positive component to the human vocal stimulus was significantly larger for the right than for the left electrodes. An even greater degree of right asymmetry was apparent in the topography of the late ERP components to the conspecific threat vocalization. This laterality was not an invariant feature of the ERP to vocal stimuli, however, because scream and alarm vocalizations did not show lateral amplitude asymmetries relative to the control stimulus. These findings raise the possibility that the right lateral dominance of the ERP to the threat and speech stimuli may have been related to the affective significance of these vocal signals for the subject. Although EEG and ERP measures in humans frequently indicate a left laterality in speech processing (Davidson, Chapman, Chapman, \& Henriques, 1990; Hahn, 1987), affective language and affective processes in general may be more strongly represented in the right hemisphere (Bradley, Cuthbert, \& Lang, 1991; Goerlik \& Ross, 1987; Tucker \& Williamson, 1984), at least for negative affect (Davidson, 1992).

The present findings certainly invite theoretical speculation, but they also raise more questions than they answer. Nevertheless, some general features have clearly emerged from these and previous psychophysiological studies of vocal perception in chimpanzees. First, like autonomic measures, eventrelated brain potentials can be highly sensitive to cognitive and affective variables, even in paradigms which do not require training or behavioral responding. Hence, they offer important approaches to the study of cognition that are broadly applicable across ontogeny and phylogeny. Second, the adaptive significance of a stimulus appears to be an important determinant of the pattern of autonomic and ERP responses in the great apes. Finally, the early emergence of specific patterns of cardiac response and the apparent lateralized processing of vocal signals in the chimpanzee support the existence of specialized vocal processing mechanisms in this species. Clearly, the generality of the present findings needs to be established, and systematic studies on the nature and origins of the observed ERP responses are necessary. The present findings suggest, however, that psychophysiological measures may offer unique insights into the cognitive and affective responses of the chimpanzee. These insights may have fundamental implications for emerging perspectives on the ontogeny and phylogeny of communication and vocal perception.

\section{Notes}


${ }^{1}$ Although neuroleptics such as droperidol may alter latencies and peak amplitudes somewhat, these effects are generally minimal in the acute condition, and they do not appear to alter the overall waveform morphology in either humans or animals (Saletu, 1977; Tasman, Hale, \& Simon, 1981). Similarly, ketamine may increase or decrease peak amplitudes depending on dose, but again does not appear to substantively alter general waveform morphology (Cohen \& Britt, 1982; Dafney \& Rigor, 1978). We have previously demonstrated that typical visual evoked potentials, including the expected ontogenetic trends, were apparent in chimpanzees under ketamine sedation (Boysen \& Berntson, 1985). Perhaps more important for the present article are the potential compromising effects of the drugs on cognitive processes, underlying the late positive potentials of interest. In fact, the influence of these cognitive operations were apparent in the obtained ERPs. In this respect, the present results probably represent conservative measures, since it is difficult to envision how the drugs employed would enhance cognitive contributions.

This research was supported in part by an NSF grant (BNS-9022355) to S.T.B., an NIMH grant (MH45460) to G.B.B., and by NIH Division of Research Resources Grant RR-00165 to the Yerkes Regional Primate Research Center. The Yerkes Center and the OSU Laboratory Animal Centers are fully accredited by the American Association for Laboratory Animal Care.

\section{References}

Arthur, D. L., \& Starr, A. (1984). Task-relevant late positive component of the auditory event-related potential in monkeys resembles P300 in humans. Science, 223, 186-188.

Aslin, R., Pisoni, D., \& Jusczyk, P. (1983). Auditory development and speech perception in infancy. In J. Campos \& M. Haith (Eds.), Mussen's handbook of child psychology: Vol 2. Infancy and developmental psychobiology. New York: Wiley.

Berntson, G. G., \& Boysen, S. T. (1989). Specificity of the cardiac response to conspecific vocalizations in chimpanzees (Pan troglodytes). Behavioral Neuroscience, 103, 235-245.

Berntson, G. G.. \& Boysen, S. T. (1990). Cardiac indices of cognition in infants, children, and chimpanzees. In C. Rovee-Collier \& L. Lipsitt (Eds.), Advances in infancy research (Vol. 6, pp. 187-220). Norwood, NJ: Ablex.

Berntson, G. G., Boysen, S. T., Bauer, H. R., \& Torello, M. S. (1990). Conspecific screams and laughter: Cardiac and behavioral responses of infant chimpanzees. Developmental Psychobiology,

Boysen, S. T., \& Berntson, G. G. (1985). Visual evoked potentials in the Great Apes. Electroencephalography and Clinical Neurophysiology, 62, 150-153.

Boysen, S. T., \& Berntson, G. G. (1986). Cardiac correlates of individual recognition in the chimpanzee (Pan troglodytes). Journal of Comparative Psychology, 100, 321-324.

Boysen, S . T., \& Berntson, G. G. (1989a). Conspecific recognition in the chimpanzee: Cardiac indices of significant others. Journal of Comparative Psychology, 103, 215-220.

Boysen, S. T., \& Berntson, G. G. (1989b). The development of numerical competence in a chimpanzee (Pan troglodytes). Journal of Comparative Psychology, 103, 23-31.

Bradley, M. M., Cuthbert, B. N., \& Lang, P. (1991). Startle and emotion: Lateral acoustic probes and the bilateral blink. Psychophysiofogy, 28, 285-295.

Bryan, Y. E., \& Newman, J. D. (1988). Influence of infant cry structure on the heart rate of the listener. In J. D. Newman (Ed.), The physiological control of mammalian vocalization (pp. 413-432). New York: Plenum Press.

Cohen, M. S., \& Britt, R. H. (1982). Effects of sodium pentobarbital, ketamine, halothane, and chloralose on brainstem auditory evoked responses. Anesthesia \& Analgesia, 61, 338-343.

Courchesne, E., Hillyard, S. A., \& Galambos, R. (1975). Stimulus novelty, task relevance, and the visual evoked potential in man. Electroencephalography and Clinical Neurophysiology, 39. 
Dafney, N., \& Rigor, B. M. (1978). Dose effects of ketamine on photic and acoustic field potentials. Neuropharmacology, 17, 85 1-862.

Davidson, R. J. (1992). Anterior cerebral asymmetry and the nature of emotion. Brain and Cognition, 20, 125-151.

Davidson, R. J., Chapman, J. P., Chapman, L. J., \& Henriques, J. B. (1990). Asymmetrical brain electrical activity discriminates between psychometrically matched verbal and spatial cognitive tasks. Psychophysiology, 27, 528-543.

DeCasper, A. J., \& Prescott, P. A. (1984). Human newborns' perception of male voices: Preference, discrimination, and reinforcing value. Developmental Psychobiology, 17, 481-491.

DeCasper, A. J., \& Spence, M. J. (1986). Prenatal maternal speech influences newborns' perception of speech sounds. Infant Behavior and Development, 9, 133-150.

Donchin, E., Karis, D., Bashore, T. R., Coles, M. G. H., \& Gratton, G. (1986). Cognitive psychophysiology and human information processing. In M. G. H. Coles, E. Donchin, \& S. Porges (Eds.), Psychophysiology: Systems, processes, and applications. (pp. 244-267). New York: Guilford Press.

Essock-Vitale, S., \& Seyfarth, R. M. (1987). Intelligence and social cognition. In B. B. Smuts, D. L. Cheney, R. M. Seyfarth, R. W. Wrangham, \& T. T. Struhsaker (Eds.), Primate societies (pp. 452461). Chicago: University of Chicago Press.

Goerlick, P. B., \& Ross, E. D. (1987). The aprosodias: Further functional-anatomical evidence for the organization of affective language in the right hemisphere. Journal of Neurology, Neurosurgery, and Psychiatry, 50, 553-560.

Goldman, D., Giri, P. R., \& O'Brien, S. J. (1987). A molecular phylogeny of the hominoid primates as indicated by two-dimensional protein electrophoresis. Proceedings of the National Academy of Sciences, 84, 3307-3311.

Goodman, M., Braunitzer, G., Stangl, A., \& Schrank, B. (1983). Evidence on human origins from haemoglobins of African apes. Nature, 303, 546-548.

Hahn, W. K. (1987). Cerebral lateralization of function: From infancy through childhood. Psychological Bulletin, 101, 376-392.

Johnson, R. (1988). The amplitude of the P300 component of the event-related potential: Review and synthesis. In P. K. Ackles, J. R. Jennings, \& M. G. H. Coles (Eds.), Advances in psychophysiology, (Vol. 3, pp. 69-137). Greenwich, CT: Jai Press.

Johnson, R. (1993). On the neural generators of the P300 component of the event-related potential. Psychophysiology, 30, 90-97.

Johnston, V. S., Miller, D. R., \& Burleson, M. H. (1986). Multiple P3s to emotional stimuli and their theoretical significance. Psychophysiology, 23, 684-694.

Kuhl, P. K. (1987a). The special-mechanisms debate in speech research: Categorization tests on animals and infants. In S. Harnad (Ed.), Categorical perception for speech (pp. 355-386). London: Cambridge University Press.

Kuhl, P. K. (1987b). Perception of speech and sound in early infancy. In P. Salapatek \& L. Cohen (Eds.), Handbook of infant perception: From perception to cognition (Vol. 2, pp. 274-382). New York: Academic Press.

van Lawick-Goodall, J. (1968). The behavior of free-living chimpanzees of the Gombe Stream Reserve. Animal Behaviour Monographs, 1, 161-311.

LeMay, M., \& Geschwind, N. (1975). Hemispheric differences in the brains of the great apes. Brain, Behavior and Evolution, 11, 48-52.

Liberman, A. M., Cooper, F. S., Shankweiler, D. P., \& Studdert-Kennedy, M. G. (1967). Perception of the speech code. Psychological Review, 74, 431-461.

Lieberman, P., Harris, K. S., Wolff, P., \& Russel, L. H. (1971). Newborn infant cry and nonhuman primate vocalization. Journal of Speech and Hearing Research, 14, 718-727. 
Marler, P., \& Tenaza, R. (1977). Signaling behavior of apes with special reference to vocalization. In T. A. Sebeok (Ed.), How animals communicate (pp. 965-1032). Bloomington, IN: Indiana University Press.

Molfese, D. L., \& Betz, J. C. (1987). Electrophysiological indices of the early development of lateralization for language and cognition and their implications for predicting later development. In $\mathrm{D}$. L. Molfese \& S. J. Segalowitz (Eds.), Developmental implications of bruin lateraliry. New York: Guilford Press.

Morse, P. A., Molfese, D., Laughlin, N. K., Linnville, S., \& Wetzel, F. (1987). Categorical perception for voicing contrasts in normal and lead-treated rhesus monkeys: Electrophysiological indices. Brain and Language, 30, 63-80.

Neville, H. J., \& Foote, S. L. (1984). Auditory event-related potentials in the squirrel monkey: Parallels to human late wave responses. Brain Research, 298, 107-116.

Newman, J. D. (1985). The infant cry of primates; An evolutionary perspective. In B. M. Lester \& C. F. Z. Boukydis (Eds.), Infant crying: Theoretical and research perspectives (pp. 307-323). New York: Plenum Press.

Newman, J. D. (1988). Physiological control of mammalian vocalization. New York: Plenum Press.

Paller, K. A., Zola-Morgan, S., Squire, L. R., \& Hillyard, S. A. (1982). Late positive event-related potentials in cynomolgus monkeys (Macaca fascicularis). Sociery for NeurOscience Abstracts, 8, 975.

Petersen, M. R. (1982). The perception of species-specific vocalizations by primates: A conceptual framework. In C. T. Snowdon, C. H. Brown, \& M. R. Peterson (Eds.), Primate communication (pp. 171-211) . London: Cambridge University.

Petersen, M. R., Zoloth, S. T., Beecher, M. D., Green, S., Marler, P. R., Moody, D. B., \& Stebbins, W. C. (1984). Neural lateralization of vocalizations by Japanese macaques: Communicative significance is more important than acoustic structure. Behavioral Neuroscience, 98, 779-790.

Picton, T. W., \& Hillyard, S. A. (1988). Endogenous event-related potentials. In T. W. Picton (Ed.), Handbook of electroencephalography and clinical neurophysiology: Vol. 3. human event-related potentials (pp. 361-426). Amsterdam: Elsevier.

Pineda, J. A., Foote, S. L., \& Neville, H. J. (1987). Long-latency event-related potentials in squirrel monkeys: Further characterization of wave form morphology, topography, and functional properties. Electroencephalography and Clinical Neurophysiology, 67, 77-90.

Pohl, P. (1983). Central auditory processing: V. Ear advantages for acoustic stimuli in baboons. Brain and Language, 20,44-53.

Polich, J. (1987). Comparison of P300 from a passive tone sequence paradigm and an active discrimination task. Psychophysiology, 24, 41-46.

Premack, D. (1986). Gavagai. Cambridge, England: Cambridge University Press.

Regan, D. (1989). Human brain elecfrophysiology. New York: Elsevier.

Ruchkin, D. S., Sutton, S., \& Mahaffey, D. (1987). Functional differences between members of the P300 complex: P3E and P3b. Psychophysiology, 24, 87-103.

Saletu, B. (1977). The evoked potential: Pharmacopsychiatry. Neuropsychobiology, 3, 75-104.

Seyfarth, R. M. (1987). Vocal communication and its relation to language. In B. B. Smuts, D. L. Cheney, R. M. Seyfarth, R. W. Wrangham, \& T. T. Struhsaker (Eds.), Primate societies (pp. 440-451). Chicago: University of Chicago Press.

Snowdon, C. T. (1982). Linguistic and psycholinguistic approaches to primate communication. In C. T. Snowdon, C. H. Brown, \& M. R. Peterson (Eds.), Primate communication (pp. 212--238). London: Cambridge University Press.

Squires, N. K., Squires, K. C., \& Hillyard, S. A. (1975). Two varieties of long-latency positive waves evoked by unpredictable auditory stimuli in man. Electroencephalography and Clinical Neurophysiology, 38, 387-401. 
Steinschneider, M., Kurtzberg, D., \&Vaughan, H. G. (1992). Event-related potentials in developmental neuropsychology. In I. Rapin \& S. J. Segalowitz (Eds.), Handbook of neuropsychology: Child neuropsychology (Vol. 6, pp. 239-299). New York: Elsevier.

Sutton, S., \& Ruchkin, D. S. (1984). The late positive complex. Annals of the New York Academy of Sciences, 425, 1-23.

Tasman, A., Hale, M. S., \& Simon, R. H. (1981). Neuroleptic drug effects on averaged evoked response augmentation-reduction in rats. Neuropsychobiology, 7, 292-296.

Trehub, S. E. (1987). Infants' perception of musical patterns. Perception and Psychophysics, 41, 635-641.

Tucker, D. M., \& Williamson, P. A. (1984). Asymmetric neural control systems in human self-regulation. Psychological Review, 91, 185-215.

Yeni-Komshian, G., \& Benson, D. (1976). Anatomical study of cerebral asymmetry in temporal lobe of humans, chimpanzees, and rhesus monkeys. Science, 192, 387-389. 